OHN has to be flexible and adaptive in order to meet the demands of this dynamic worker health environment. One solution to this complex health milieu is an integrated model of $\mathrm{OH}$ services in order to meet the difficulty of the health and wellness demands of workers in a complicated environment of risk.

\section{COMPARING TWO APPROACHES TO SCORING ALLOSTATIC LOAD IN BRAZILIAN CIVIL SERVANTS}

${ }^{1,2}{ }^{2}$ N Eto*, ${ }^{1}$ RS Santos, ${ }^{1}$ ECP Melo, ${ }^{3}$ RH Griep, ${ }^{2} \mathrm{~S}$ Toivanen. ${ }^{1}$ National School of Public Health, Oswaldo Cruz Foundation, Rio de Janeiro, Brazil; ${ }^{2}$ Centre for Health Equity Studies, Stockholms Universitet, Karolinska Institutet, Stockholm, Sweden; ${ }^{3}$ Laboratory of Health and Environment Education, Oswaldo Cruz Foundation, Rio de Janeiro, Brazil

\subsection{6/oemed-2018-ICOHabstracts.884}

Introduction Several international studies have used the allostatic load as an important multi-dimensional index to indicate chronic stress. Measurement of allostatic load has been done through parameters from various biological systems. Through its measurement, it's possible to assess the consequences of chronic stress on several systems, and also predict, prevent or delay chronic diseases that may occur later. Despite its importance, methodological issues regarding its operationalization remains. The aim of our study was to compare two approaches to scoring allostatic load.

Methods Data were obtained from the baseline of the Brazilian Longitudinal Study of Adult Health (ELSA-Brasil). The sample included 10965 active civil servants aged 34-74 years old. The allostatic load was measured based on 15 biologic parameters, including neurophysiological, metabolic, cardiovascular and inflammatory measurements. We compared two approaches to scoring allostatic load - based on clinical and risk quartile thresholds. Socioeconomic variables such as age, gender, skin colour and educational level were analysed. We performed descriptive analyses as mean, standard deviation and prevalence and conduced Student's $t$ test, ANOVA and linear regression analysis. Data were analysed using $\mathrm{R}$.

Results The findings showed that the percentage of individuals with high risk biologic parameters were different according to allostatic load scoring approaches. The mean values of the allostatic load clinically based were higher in all socioeconomic variables compared to the allostatic load quartile based. Nevertheless, in the linear regression model the magnitude of association observed was similar when comparing the both allostatic load scoring approaches.

Discussion This is the first Brazilian study that explores different approaches to scoring allostatic load. Besides, our study highlight the importance of studying the allostatic load at Brazilian context and how it can be used as a potential tool to occupational health and practice and contribute to prevent chronic diseases related to the chronic exposure to stress.

\section{PREVALENCE OF GASTROINTESTINAL DISEASES IN BRAZILIAN WORKERS RECEIVING SICK LEAVE BENEFITS - A RETROSPECTIVE STUDY}

IS Marineli, NC Rodrigues, VR Silva, LAF Cardillo, LR Ferreira. Centro Universitário das Faculdades Associadas de Ensino - FAE, São João da Boa Vista, Brazil

10.1136/oemed-2018-ICOHabstracts.885
Introduction Gastrointestinal diseases in Brazil can be responsible for work disability, making employees eligible to receive sick leave benefits. The aim of this study was to determine the gastrointestinal tract diseases causing the most frequent number of sick leave benefits from the National Institute of Social Security (INSS) and the profile of these workers to understand better the occurrence of these pathologies amongst workers.

Methods A retrospective study was conducted between January 2014 and February 2017. We selected 3260 patients diagnosed with gastrointestinal diseases, who had received temporary social security benefits from INSS. The samples were submitted to data collection including: sex, age, occupation, and international classification of diseases (ICD). Diseases with higher prevalence were analysed.

Results The study revealed that the most prevalent gastrointestinal disease included abdominal hernias (ICD K40-K42-K43) in 1328 workers, cholelithiasis (ICD K80) in 1298 patients, acute appendicitis (ICD K35) 634 cases. The results showed that $54 \%$ were males, with a mean age of 43 years. However, cholelithiasis affected mostly females. Amongst the hernias, the most prevalent was inguinal hernia followed by umbilical and ventral hernias. All of the workers received temporary sickleave benefit, but only $0.05 \%$ had the benefit of disability retirement and $0.35 \%$ sick-leave benefit due to work-related accidents (associated with hernia).

Discussion The data obtained allowed us to evaluate that the most frequent gastrointestinal diseases associated with sickleave benefits were those related to surgical management. The appearance of abdominal wall hernias may occur due to increased intra-abdominal pressure, associated with intense physical exertion made by some workers. Dietary habits are a risk factor for appendicitis, especially a diet with low fibre intake. Fatty foods, on the other hand, may influence the occurrence of cholelithiasis. These data may help understand the main factors associated with work disability due to gastrointestinal diseases.

\section{SICK LEAVE BENEFITS BY DIABETES MELLITUS: A RETROSPECTIVE EPIDEMIOLOGICAL STUDY}

DVS Vitor*, VR Batalini, RV Brito, CA Baptista, PI Scardovelli, LR Ferreira. UNIFAE School of Medicine, São João da Boa Vista, São Paulo State, Brazil

\subsection{6/oemed-2018-ICOHabstracts.886}

Introduction Diabetes mellitus is a disease that has a high prevalence around the world. In 2014, the World Health Organisation estimated that 422 million adults had the disease, worldwide. It is classified as being a chronic non-transmissible disease, and it is one of the main causes of disability, which can negatively affect productivity in active workers. In Brazil, the National Institute of Social Security (INSS) is responsible for granting benefits and salaries in cases of absenteeism due to illness.

Methods A retrospective study based on analysis of 184 patients who requested sick leave benefits due to diabetes mellitus from the Brazilian National of Social Security Institute (INSS), characterising the age, gender and employment situation through the ICD-10 (E10, E11 and E14) from January 2014 to February 2016.

Results The results showed that diabetes mellitus represented $34.2 \%$ of all sick leave requests associated with endocrine 